\title{
Glottal Closure in Women with No Voice Complaints or Laryngeal Disorders
}

\author{
Mara Keli Christmann ${ }^{1}$ \\ ${ }^{1}$ Department of Phonoaudiology, Universidade Federal de Santa \\ Maria, Santa Maria, RS, Brazil \\ 2 Department of Psychiatry, Universidade Federal do Rio Grande do \\ Sul, Porto Alegre, RS, Brazil \\ 3 Postgraduation Program in Human Communication, Universidade \\ Federal de Santa Maria, Santa Maria, RS, Brazil
}

Carla Aparecida Cielo ${ }^{1}$ Karine Schwarz ${ }^{2 \odot}$ Leila Susana Finger ${ }^{3}$ Joziane Moraes Lima ${ }^{1}$

\begin{abstract}
Address for correspondence Karine Schwarz, PhD, Departamento de Fonoaudiologia, Instituto da Voz, Dom Pedro II, 891/604, 91450-155, Porto Alegre, RS, Brazil (e-mail: fonoka@Hotmail.com).
\end{abstract}

Int Arch Otorhinolaryngol 2019;23:e384-e388.

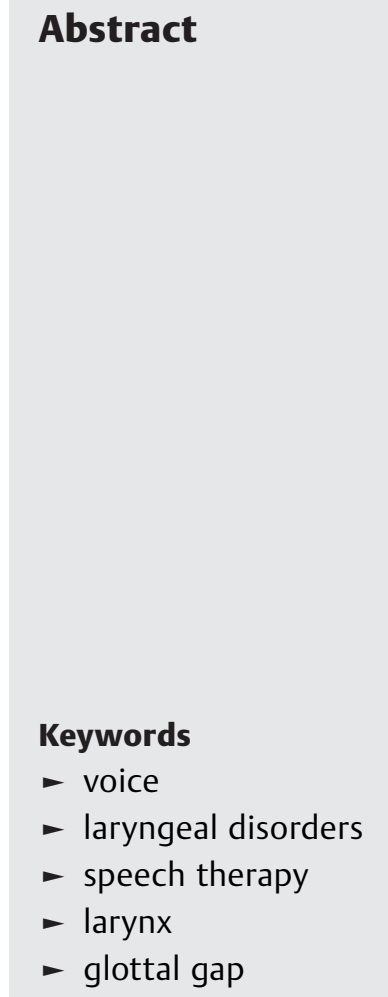

Introduction The understanding of normal vocal production is essential to guide any voice professional as it is fundamental to understand the effects of the posterior glottal gap on the vocal quality.

Objective The aim of the present study was to verify the association between glottic closure, acoustic parameters, and some characteristics of the videolaryngostroboscopy of young women without vocal complaints nor laryngeal disorders.

Methods This is a cross-sectional study with 56 women between 20 and 30 years old who underwent videolaryngostroboscopy. The acoustic parameters of the vowel /a:/ were analyzed using the Praat software, Release 4.6.10 (Paul Boersman and David Weenik, Amsterdam, Netherlands).

Statistical Analysis The chi-squared, Fischer, and Kruskall-Wallis tests were applied, with $5 \%$ significance.

Results Significant occurrence of posterior glottal gap $(85.71 \%, p<0.001)$, of normal vocal folds vibration amplitude $(82.14 \%, p<0.001)$, and of absence of significant constriction of the laryngeal vestibule $(98.21 \%, p<0.001)$; no significant association of the glottic closure with the vocal acoustic parameters; no significant association of glottic closure, vocal folds vibration amplitude, and constriction of the laryngeal vestibule.

Conclusion There was a predominance of posterior glottal gap, normal vocal folds vibration amplitude, and absence of laryngeal vestibule constriction, and no relation with the acoustic parameters, suggesting that the posterior glottal gap did not generate impact on the vocal production of the young adult women studied.

\section{Introduction}

The glottic proportion reflects the length relation between the membrane and the cartilaginous portions of the vocal folds. ${ }^{1,2}$ In female larynxes, a glottic proportion of 1:1 occurs, so the approximation of the arytenoids cartilages is not complete, creating the posterior glottal gap to phonation in women. ${ }^{3,4}$
The glottal gap is frequently related to the occurrence of dysphonia, but studies have revealed that the posterior glottal gap can be found in voices without alteration, ${ }^{2-9}$ so it is considered the standard glottic closure in women with no voice disorders.

The understanding of the vocal production without alterations is fundamental to guide the voice professionals, as it is fundamental to understand the effects of the posterior glottal received

December 22, 2017

accepted

October 12, 2018
DOI https://doi.org/

10.1055/s-0038-1676108. ISSN 1809-9777.
Copyright (e 2019 by Thieme Revinter

Publicações Ltda, Rio de Janeiro, Brazil
License terms

()(1) $\Theta \circledast$ 
gap on the vocal quality. This gap is considered physiological in women. In the present study, we have verified the association among glottic closure, acoustic parameters, and some characteristics of the videolaryngostroboscopy of young women without vocal complaints nor laryngeal disorders.

\section{Materials and Methods}

The research was characterized as a cross-sectional study, previously approved by the Ethics Committee in Research of our institution (23081.016945/2010-76). The data collection started after all the participants read and signed the Informed Consent (IC), which was created as recommended by the Resolution 466/12 of the Brazilian National Health Council, authorizing the storage and use of the information in scientific research, as long as the identity of the participants is not disclosed.

The inclusion criteria were: females; aged between 20 and 40 years old-within this age range, the vocal apparatus has not suffered aging-related hormonal or structural influence, ${ }^{7,10}$ and no further alterations due to the mutational voice period are expected ${ }^{2}$; and IC adhesion.

The exclusion criteria were: laryngeal affections; vocal complaints, such as hoarseness, vocal fatigue, voice failures, or throat burning sensation, since these are symptoms suggestive of some type of vocal alteration at the organic or at the behavioral level $2,7,10,11$; report of hormonal changes arising from pregnancy, from the menstrual or the premenstrual period on the evaluation day; history of neurological, psychiatric, endocrinological, or gastric ${ }^{2}$ disease that could influence the vocal performance or the understanding of commands during the evaluations; flu, respiratory allergies, or another disease that could limit the vocal performance on the evaluation day; frequent alcohol use and/or smoking habit, as they may cause organic vocal problems; speech-language and/or previous otorhinolaryngological treatment, to discard the possibility of any vocal disorder (even the ones already treated) and/or any vocal conditioning with vocal techniques; auditory alterations, since they may change the vocal self-monitoring, compromising the voice quality; changes to the stomatognathic system that could interfere in the speech articulation, compromising the voice; being a voice professional, to avoid any type of vocal conditioning which could influence the results. ${ }^{2}$

For the application of the inclusion and exclusion criteria, the volunteers read and signed the IC, answered the medical history interview, performed an otorhinolaryngological evaluation, and underwent a phonoaudiological screening that included an orofacial myofunctional assessment and a hearing evaluation.

Five women were excluded (three due to laryngeal affections, one for having already underwent a prior speechlanguage treatment, and one for being a smoker); the study group comprised 56 adult women without vocal complaints and with normal larynx, aged between 20 and 30 years old (average of $25 \pm 1$ years old).

For the data collection, an otorhinolaryngologist performed the videolaryngostroboscopy examination with a rigid laryngoscope (Hopkins, Atmos Medizintechnik GmbH \& Co., Lenzkirch, Germany), maintaining the same distance and angle from the larynx, without use of anesthetic and with image recording on DVD. The volunteers were advised to perform the sustained emission of the vowels /e/ and /i/ in vocal chest modal voice, after deep inspiration, until the end of the expiration. Afterwards, these images were analyzed by three otolaryngologists experienced in laryngology, independently from each other, and the predominant opinion among the judges was considered.

The analysis of the laryngeal images assessed the glottic closure (complete, anterior gap, irregular gap, fusiform gap, posterior glottal gap, middle-posterior triangular gap, gap in hourglass); the amplitude of vibration (normal, restricted, increased, greatly increased); the laryngeal vestibule constriction (absent or present: medial, anteroposterior, global). This assessment was performed through a protocol developed by the authors, based on the literature. ${ }^{7,12}$

On the same occasion of the completion of the videolaryngostroboscopy examination, in a quiet room, with the women in the orthostatic position, after deep inspiration, the sustained emission of the vowel /a/ in the usual pitch and loudness by emitting the sound during the maximum phonation time was recorded. A Shure 57A unidirectional microphone (Shure Inc., Niles, IL, USA) coupled to a Sony MZR7000DPC digital recorder (Sony Corporation, Tokyo, Japan) was positioned at $90^{\circ}$ and at a distance of $4 \mathrm{~cm}$ in front of the mouth of the individual. ${ }^{2,10}$

The sample of the vowel /a:/ was used for the acoustic analysis of the glottal source. It was converted to $44 \mathrm{kHz}, 16$ bits with the WavePad software, Release 5.10 (NCH Software, Greenwood Village, CO, USA), and the beginning of the emission was excluded so that the vocal attack did not interfere in the data analysis. ${ }^{13}$ The vocal acoustic parameters measured were: fundamental frequency (F0); minimum frequency; maximum frequency jitter (local); jitter (local, absolute); jitter (rap); jitter (ppq5); jitter (ddp); shimmer (local); shimmer (local, dB); shimmer (apq3); shimmer (apq5); shimmer (apq11); shimmer (ddp); harmonic-noise ratio (HNR); and noise-harmonic ratio (NHR). The measurement of the vocal acoustic parameters was made with the Praat software, Release 4.6.10 (Paul Boersman and David Weenik, Amsterdam, Netherlands).

The statistical data analysis used the chi-squared, Fischer, and Kruskall-Wallis tests, with a significance of $5 \%$.

\section{Results}

From the data on - Table 1, a significant occurrence of the posterior glottal gap was verified when compared with the complete glottic closure. The normal vocal folds vibration amplitude was significant in relation to the increased vibration amplitude. A significant absence of laryngeal vestibule constriction was also observed.

- Table 2 shows the comparison among the following variables: type of closing, vibration amplitude, and laryngeal vestibule constriction. No significant result was observed.

- Table 3 shows that there was no significant difference between the measurements of the vocal acoustic parameters of women with complete glottic closure and with posterior glottal gap. 
Table 1 Results of the videolaryngostroboscopy

\begin{tabular}{|c|c|c|c|}
\hline & $n=56$ & $\%$ & p-value \\
\hline \multicolumn{4}{|l|}{ Glottic closure } \\
\hline Complete & 8 & $14 \pm 2$ & \multirow[t]{2}{*}{$<0.001^{*}$} \\
\hline Posterior glottal gap & 48 & $86 \pm 2$ & \\
\hline \multicolumn{4}{|c|}{ Vocal folds vibration amplitude } \\
\hline Increased & 1 & $2 \pm 2$ & \multirow[t]{3}{*}{$<0.001^{*}$} \\
\hline Decreased & 9 & $16 \pm 2$ & \\
\hline Normal & 46 & $82 \pm 2$ & \\
\hline \multicolumn{4}{|c|}{ Laryngeal vestibule constriction } \\
\hline Absent & 55 & $98 \pm 2$ & \multirow[t]{2}{*}{$<0.001^{*}$} \\
\hline Present & 1 & $2 \pm 2$ & \\
\hline
\end{tabular}

Chi-squared test; $p$-value $=0.05 ;{ }^{*}$ significance.

Table 2 Type of closing, vibration amplitude, and laryngeal vestibule constriction variables

\begin{tabular}{|c|c|c|c|}
\hline & \multicolumn{3}{|c|}{ Glottic closure } \\
\hline & $\begin{array}{l}\text { Complete } \\
\%(n)\end{array}$ & $\begin{array}{l}\text { Posterior glottal gap } \\
\%(n)\end{array}$ & $n$ \\
\hline \multicolumn{4}{|c|}{${ }^{*}$ Vocal folds vibration amplitude } \\
\hline Decreased & $\begin{array}{l}13 \% \\
(1)\end{array}$ & $\begin{array}{l}17 \pm 2 \% \\
(8)\end{array}$ & 9 \\
\hline Normal & $\begin{array}{l}87 \% \\
(7)\end{array}$ & $\begin{array}{l}81 \pm 2 \% \\
(39)\end{array}$ & 46 \\
\hline Increased & $\begin{array}{l}0 \% \\
(0)\end{array}$ & $\begin{array}{l}2 \pm 2 \% \\
(1)\end{array}$ & 1 \\
\hline \multirow[t]{3}{*}{$n$} & 8 & 48 & 56 \\
\hline & \multicolumn{3}{|c|}{ Glottic closure } \\
\hline & $\begin{array}{l}\text { Complete } \\
\%(n)\end{array}$ & $\begin{array}{l}\text { Posterior glottal gap } \\
\%(n)\end{array}$ & \\
\hline \multicolumn{4}{|c|}{ *Laryngeal vestibule constriction } \\
\hline Absent & $\begin{array}{l}100 \% \\
(8)\end{array}$ & $\begin{array}{l}98 \pm 2 \% \\
(47)\end{array}$ & 55 \\
\hline Present & $\begin{array}{l}0 \% \\
(0)\end{array}$ & $\begin{array}{l}2 \pm 2 \% \\
(1)\end{array}$ & 1 \\
\hline \multirow[t]{3}{*}{$n$} & 8 & 48 & 56 \\
\hline & \multicolumn{3}{|c|}{ Laryngeal vestibule constriction } \\
\hline & $\begin{array}{l}\text { Absent } \\
\%(n)\end{array}$ & $\begin{array}{l}\text { Present } \\
\%(n)\end{array}$ & \\
\hline \multicolumn{4}{|c|}{ *Vocal folds vibration amplitude } \\
\hline Decreased & $\begin{array}{l}16 \pm 2 \% \\
(9)\end{array}$ & $\begin{array}{l}0 \% \\
(0) \\
\end{array}$ & 9 \\
\hline Normal & $\begin{array}{l}82 \pm 2 \% \\
(45)\end{array}$ & $\begin{array}{l}100 \% \\
(1)\end{array}$ & 46 \\
\hline Increased & $\begin{array}{l}2 \pm 2 \% \\
(1)\end{array}$ & $\begin{array}{l}0 \% \\
(0)\end{array}$ & 1 \\
\hline$n$ & 55 & 1 & 56 \\
\hline
\end{tabular}

${ }^{*}$ Fisher exact tests; $p$-value $=1.000$.
Table 3 Relationship between glottic closure and vocal acoustic parameters, with measurements obtained through Praat

\begin{tabular}{|c|c|c|c|c|c|}
\hline & \multicolumn{4}{|c|}{ Glottic closure } & \multirow[t]{3}{*}{ p-value } \\
\hline & \multicolumn{2}{|c|}{ Complete } & \multicolumn{2}{|c|}{$\begin{array}{l}\text { Posterior glottal } \\
\text { gap slit }\end{array}$} & \\
\hline & Average & SD & Average & SD & \\
\hline $\begin{array}{l}\text { f0 median } \\
\text { (HZ) }\end{array}$ & 206.5 & 27.23 & 178.7 & 69.56 & 0.399 \\
\hline $\begin{array}{l}\text { f0 average } \\
\text { (HZ) }\end{array}$ & 202.1 & 37.88 & 199.7 & 26.73 & 0.690 \\
\hline $\begin{array}{l}\text { Standard } \\
\text { deviation } \\
\text { f0 }(\mathrm{Hz})\end{array}$ & 5.72 & 10.71 & 1.91 & 0.49 & 0.656 \\
\hline $\begin{array}{l}\text { Minimum } \\
\text { frequency } \\
(\mathrm{Hz})\end{array}$ & 185.89 & 45.40 & 194.68 & 25.28 & 0.796 \\
\hline $\begin{array}{l}\text { Maximum } \\
\text { frequency } \\
(\mathrm{Hz})\end{array}$ & 211.82 & 38.29 & 204.54 & 26.43 & 0.373 \\
\hline $\begin{array}{l}\text { Jitter local } \\
(\%)\end{array}$ & 0.44 & 0.32 & 0.34 & 0.10 & 0.246 \\
\hline $\begin{array}{l}\text { Jitter local, } \\
\text { absolute }(\mu \mathrm{s})\end{array}$ & 18.56 & 7.18 & 17.72 & 7.41 & 0.673 \\
\hline Jitter rap (\%) & 0.23 & 0.08 & 0.19 & 0.06 & 0.214 \\
\hline $\begin{array}{l}\text { Jitter ppq5 } \\
(\%)\end{array}$ & 0.26 & 0.21 & 0.20 & 0.05 & 0.276 \\
\hline Jitter ddp (\%) & 0.71 & 0.28 & 0.59 & 0.18 & 0.281 \\
\hline $\begin{array}{l}\text { Shimmer } \\
\text { local (\%) }\end{array}$ & 3.13 & 2.50 & 2.75 & 1.20 & 0.673 \\
\hline $\begin{array}{l}\text { Shimmer } \\
\text { local dB (dB) }\end{array}$ & 0.37 & 0.69 & 0.24 & 0.11 & 0.519 \\
\hline $\begin{array}{l}\text { Shimmer } \\
\text { apq3 (\%) }\end{array}$ & 1.69 & 1.29 & 1.51 & 0.60 & 0.796 \\
\hline $\begin{array}{l}\text { Shimmer } \\
\text { apq5 (\%) }\end{array}$ & 2.47 & 3.16 & 1.76 & 0.87 & 0.425 \\
\hline $\begin{array}{l}\text { Shimmer } \\
\text { apq11 (\%) }\end{array}$ & 2.35 & 1.87 & 2.03 & 1.02 & 0.459 \\
\hline $\begin{array}{l}\text { Shimmer } \\
\text { dda (\%) }\end{array}$ & 5.18 & 3.84 & 4.55 & 1.81 & 0.738 \\
\hline NHR & 0.01 & 0.01 & 0.01 & 0.00 & 0.607 \\
\hline HNR (dB) & 21.30 & 3.67 & 20.97 & 2.56 & 0.756 \\
\hline
\end{tabular}

Abbreviation: SD, standard deviation.

Mann-Whitney test; $p$-value $=0.05$.

\section{Discussion}

We have evaluated the glottic closure of 56 women aged between 20 and 30 years old, with an average age of $25 \pm 1$ years old, without vocal complaints nor laryngeal affections. A significant occurrence of posterior glottal gap, normal vocal folds vibration amplitude, and absence of laryngeal vestibule constriction was observed (-Table 1 ). In all the vocal acoustic parameters measured, no significant difference was observed between women with complete glottic closure and women with posterior glottal gap. (-Table 3). 
The significant occurrence of posterior glottal gap is in line with the literature that considers this gap a frequent characteristic found in women due to the typical glottic proportion of the female larynx, in which the arytenoid approximation is not complete. ${ }^{2-4,7}$ However, the posterior glottis in women has an area of $\sim 31 \mathrm{~mm}^{2}$, that is, it represents $60 \%$ of all the glottic rhyme; in men, this area is of $45 \mathrm{~mm}^{2}$, which corresponds to $56 \%$ of all the glottic rhyme. ${ }^{14}$ This suggests a similarity between men and women in the area of the posterior region of the glottis, and may explain why $14 \pm 2 \%$ ( 8 women) were found to have complete glottic closure in the present study (-Table $\mathbf{1}$ ).

In the present study, $86 \pm 2 \%$ of the women presented posterior glottal gap ( - Table 1 ), similarly to what has been described by other works. ${ }^{3,4,7}$ In a case study that examined the glottic closure of young women without vocal complaints, the occurrence of posterior glottal gap in three out of the five women evaluated was observed. ${ }^{13}$ In another study, ${ }^{6}$ the impact of different phonation modes on the glottic closure of 21 young women with normal voices was evaluated, and it was verified that the glottic closure was typically incomplete in this group. In addition, it has been found that different vocal techniques, such as nasal sounds, may aid glottic closure.

To maintain a stable vocal emission, a balance between the aerodynamic forces of the pulmonary air flow and the myoelastic larynx forces is needed. ${ }^{2}$ The air output caused by the posterior glottal gap can favor the predominance of the aerodynamic forces, conferring aperiodic energy or a nasal voice. ${ }^{7}$ This air output may unbalance the pneumophonic coordination and generate long-term instabilities, such as fluctuations, or a decline in pitch or loudness.

The absence of a significant difference between women with complete glottic closure and women with posterior glottal gap, in all the vocal acoustic parameters measured ( - Table 3), and the significant occurrence of normal vocal folds vibration amplitude, as well as the significant absence of laryngeal vestibule constriction in our study (-Table $\mathbf{1}$ ), show that the occurrence of posterior glottal gap did not generate an impact on the vocal acoustic parameters measured. As other studies show, ${ }^{2-4,7}$ the posterior glottal gap is considered physiological and is restricted to the respiratory region of the larynx. The women with posterior glottal gap were not the same presenting decreased vocal folds vibration amplitude or laryngeal vestibule constriction, (-Table 2); this reinforces considering the posterior glottal gap as physiological.

In the present study, the average of the fundamental frequency (f0 median) of the women with posterior glottal gap was $178.7 \mathrm{~Hz}$ (-Table 3 ), which is compatible with the results found in other studies with women without vocal complaints nor laryngeal affections. ${ }^{10-13}$ The values of jitter, shimmer, NHR, and HNR ( - Table 3 ) also match those from other studies with women without vocal complaints nor laryngeal affections. ${ }^{10,13}$

The vocal production is not entirely periodic; any human vocal sign presents disturbances even when executed by fully concentrated non-dysphonic individuals. The disturbances may be caused by different laryngeal configurations or muscular forces; by variations in the source-filter relation during phonation; by the airflow through the glottis during the emission, which generates instability and turbulence; and by the influence of the respiratory level on the emission. ${ }^{9}$ In the present study, the air flowing through the posterior glottal gap did not generate significant changes in the short term disturbances, as shown by the jitter and shimmer measurements presented in - Table 3.

These findings are different from the ones in another study that used a computerized model of the laryn $x^{8}$, which found acoustic and aerodynamic changes due to the posterior glottal gap, as the voiceless airflow through the glottis in the vocal tract changed the aerodynamics, the acoustics, and the subsequent dynamic behavior of the larynx. Computerized models may still fail in accounting for all the details involved in the vocal production present in the human larynx.

In the present study, the sample size and the age range prevented us from extending the conclusions to all women.

Thus, other studies may explore the human vocal characteristics regarding the types of glottic closure present in other populations and within other age ranges.

\section{Conclusion}

Young adult women showed a predominance of posterior glottal gap, normal vocal folds vibration amplitude, absence of laryngeal vestibule constriction, and no relation with the measurements of vocal acoustic parameters. The physiological posterior glottal gap did not influence the measurements of the vocal acoustic parameters in the present study.

\section{Acknowledgments}

This study was financed in part by the Coordenação de Aperfeiçoamento de Pessoal de Nível Superior - Brasil (CAPES) - Finance Code 001. C. A. Cielo acknowledges support from Brazilian agency CNPq (Grant 301326/20177). We also acknowledge CNPQ and CAPES for provide financial support through scholarships.

The authors thank Prof L S Dorneles (English revision).

\section{References}

1 Herbst CT, Lohscheller J, Švec JG, Henrich N, Weissengruber G, Fitch WT. Glottal opening and closing events investigated by electroglottography and super-high-speed video recordings. J Exp Biol 2014;217(Pt 6):955-963

2 Behlau M. Voz o Livro do Especialista. Rio de Janeiro: Revinter; 2008.

3 Schneider B, Bigenzahn W. Influence of glottal closure configuration on vocal efficacy in young normal-speaking women. J Voice 2003;17(04):468-480

4 Linville SE. Glottal gap configurations in two age groups of women. J Speech Hear Res 1992;35(06):1209-1215

5 Chandran S, Hanna J, Lurie D, Sataloff RT. Differences between flexible and rigid endoscopy in assessing the posterior glottic chink. J Voice 2011;25(05):591-595 
6 Khoddami SM, Mehri A, Jahani Y. The role of sex in glottis closure in people with normal voice. Audiol 2011;20(01): 64-72

7 De Bodt MS, Clement G, Wuyts FL, Borghs C, Van Lierde KM. The impact of phonation mode and vocal technique on vocal fold closure in young females with normal voice quality. J Voice 2012; 26(06):818.e1-818.e4

8 Zañartu M, Galindo GE, Erath BD, Peterson SD, Wodicka GR, Hillman RE. Modeling the effects of a posterior glottal opening on vocal fold dynamics with implications for vocal hyperfunction. J Acoust Soc Am 2014;136(06):3262-3271

9 Zhang Z. Regulation of glottal closure and airflow in a threedimensional phonation model: implications for vocal intensity control. J Acoust Soc Am 2015;137(02):898-910

10 Gama ACC, Behlau MS. Estudo da constância de medidas acústicas de vogais prolongadas e consecutivas em mulheres sem queixa de voz e em mulheres com disfonia. Rev Soc Bras Fonoaudiol 2009;14 (01):8-14

11 Brockmann M, Drinnan MJ, Storck C, Carding PN. Reliable jitter and shimmer measurements in voice clinics: the relevance of vowel, gender, vocal intensity, and fundamental frequency effects in a typical clinical task. J Voice 2011;25(01):44-53

12 Andrade-Miranda G, Godino-Llorente JI, Moro-Velázquez L, Gómez-García JA. An automatic method to detect and track the glottal gap from high speed videoendoscopic images. Biomed Eng Online 2015;14(01):100

13 Finger LS, Cielo CA, Schwarz K. Acoustic vocal measures in women without voice complaints and with normal larynxes. Rev Bras Otorrinolaringol (Engl Ed) 2009;75(03):432-440

14 Dedivitis RA. Anatomia da Laringe. In: DEDIVITIS, RA. e BARROS, APB. Métodos de avaliação e diagóstico de laringe e voz. São Paulo: Lovise; 2002. Cap. 2, p5-37. 